\title{
Transmisión del riesgo de crédito en el sector bancario Europeo: crisis subprime y deuda soberana
}

\section{Credit risk transmission in the European banking sector: the case of the subprime and Eurozone debt crises}

\author{
${\text { Laura Ballester } \text { Miquel }^{\mathrm{a} *} \text {, Ana González-Urteaga }}^{\mathrm{b}}$ and David Tudela Ferrándiz ${ }^{\mathrm{c} \dagger}$ \\ ${ }^{a}$ Departamento de Economía Financiera y Actuarial, Facultad de Economía, Universidad de \\ Valencia, Valencia, Spain; ${ }^{b}$ Departamento de Gestión de Empresas, Universidad Pública de \\ Navarra, Pamplona, Spain; ${ }^{\circ}$ Banco de España, Barcelona, Spain
}

(Received 28 November 2013; accepted 13 September 2014)

\begin{abstract}
El objetivo del presente trabajo es analizar en profundidad la transmisión del riesgo de crédito, aproximado por los CDS spreads, en el sector bancario europeo durante el periodo 2006-2012, intentando dar respuesta a diversas cuestiones: (i) ¿existe evidencia de transmisión del riesgo de crédito entre las entidades financieras europeas de la Eurozona y las que no pertenecen a dicha zona?, (ii) ¿es esta transmisión bidireccional o unidireccional?, (iii) concretamente, ¿qué países han liderado dicha transmisión?, y (iv) ¿cómo se ha visto afectada dicha transmisión con las recientes crisis financieras? Los resultados indican un cambio significativo en la transmisión del riesgo de crédito con el estallido de la crisis subprime, con un efecto notable proveniente de los bancos de la Eurozona hacia los que no pertenecen a dicha zona.
\end{abstract}

Palabras clave: CDS spreads; riesgo de crédito; sector bancario; causalidad Granger

The aim of this paper is to analyse in depth the transmission of credit risk, approximated by the CDS spreads, in the European banking sector during the period 2006-2012, attempting to respond to several questions: (i) is there any evidence of credit risk transmission between the European financial institutions in the Eurozone and those not belonging to this zone?, (ii) is this transmission bidirectional or unidirectional?, (iii) specifically, what countries have led such transmission? and (iv) how this transmission has been affected by the recent financial crisis? The results indicate a significant change in credit risk transmission with the outbreak of the subprime crisis, with a remarkable effect from the Eurozone banks to those not belonging to this zone.

Keywords: CDS spreads; credit risk; banking sector; Granger causality

JEL clasificación: C32; G10; G15

\section{Introduccion}

La crisis de las hipotecas subprime iniciada en 2007 en el mercado estadounidense se extendió a otros instrumentos, instituciones y mercados financieros internacionales con gran facilidad. El canal más directo a través del cual se produjo dicha transmisión fue el

\footnotetext{
*Corresponding author. Email: laura.ballester@uv.es

${ }^{\dagger}$ Las opiniones y análisis que aparecen en el documento son responsabilidad de los autores y por tanto no necesariamente coinciden con las del Banco de España.
} 
contagio de crédito vía los mercados de activos derivados. La quiebra de Lehman Brothers en 2008 supuso no sólo el colapso del sector financiero internacional, sino que además desencadenó una crisis financiera global, cuya repercusión en Europa fue una consecuencia inmediata, tanto a nivel país como en el sector bancario. Debido al contagio financiero y ante la imposibilidad de sostener su deuda pública, Grecia se vio obligada a solicitar ayuda externa en 2010. Grecia fue el primer país europeo en ser rescatado, y posteriormente Irlanda y Portugal. Esto desencadenó la llamada crisis de deuda soberana del euro, y donde la propia estructura de la Eurozona como unión monetaria pero sin unión fiscal ha contribuido en gran medida. La fragmentación se hacía más patente en Europa, evidenciando la fragilidad financiera de la Eurozona, incluso entre los países del sur de Europa con problemas de deuda frente a países de la zona euro considerados aún estables como Alemania o Luxemburgo. ${ }^{1}$ Tras el segundo rescate a Grecia en 2011, las tensiones en la Eurozona se intensificaron y también España se convirtió en motivo de preocupación ante su incapacidad de acceder a los mercados de capitales, conduciendo a un rescate de sus bancos.

Dada la actual interconexión en el sistema financiero europeo, si un determinado país entra en recesión o se aproxima al default, no sólo afecta a su propia deuda sino que también pone en situación de riesgo a los sistemas bancarios de países prestamistas afectando a la deuda privada externa, enfrentándose a pérdidas provocadas por lo que se conoce como contagio financiero. Este hecho, se intensifica de manera sustancial si además existen entre ambos países contratos para la protección del crédito. Los países más vulnerables y en situación de 'evento de crédito' tendrán que transferir cuantías mucho más elevadas a los países prestamistas para proteger sus instrumentos de deuda como son los bonos soberanos. La elevada transmisión de fondos desde las entidades financieras a las naciones europeas, principalmente en la Eurozona, ha provocado una rápida transferencia del riesgo de crédito hacia otros países generando posiciones arriesgadas, apalancamiento y especulación. La vulnerabilidad de las entidades financieras europeas es todavía hoy un hecho de suma importancia, en gran parte debido a la gran cantidad de deuda soberana que tienen en su propiedad. En consecuencia, se ha intensificado la preocupación sobre la solvencia o riesgo de crédito tanto de los sistemas bancarios europeos como de la deuda soberana.

En este contexto, analizar y cuantificar los canales de transmisión del riesgo de crédito de las entidades financieras europeas se ha convertido en una cuestión primordial que preocupa tanto a reguladores, profesionales como a académicos. Sin embargo, ha recibido poca atención en la literatura reciente, ${ }^{2}$ que se ha centrado principalmente en el análisis del contagio financiero en Europa desde distintos puntos de vista, estudiando las relaciones entre diferentes mercados o analizando interconexiones entre ellos. Gentile y Giordano (2012) analizan, para un periodo muestral comprendido entre 2003 y 2012, los cambios en la existencia y dirección de la causalidad entre los mercados de acciones y bonos de un conjunto de países europeos. Concluyen que los patrones de causalidad han cambiado durante el periodo de crisis actual y que el efecto contagio entre los distintos países tienen una fuerte influencia en los precios de los activos considerados. GómezPuig y Sosvilla-Rivero (2013) presentan evidencia de la existencia de un incremento tanto de relaciones causales como de un efecto contagio en la reciente crisis financiera al analizar el comportamiento de la deuda pública (bonos a diez años) emitida por países miembros de la Eurozona, más concretamente por las economías más periféricas con problemas de deuda soberana conocidas como PIIGS (Portugal, Italia, Irlanda, Grecia, y España). 
Ehlers, Gürtler, y Olboeter (2010) estudian, mediante el concepto de causalidad en el sentido de Granger, la transferencia de información existente entre el mercado europeo de acciones y el de derivados de riesgo de crédito CDS (credit default swaps), considerado como proxy del riesgo de crédito, y utilizando distintos índices para ambos mercados. Como principal conclusión exponen que la transferencia de información del mercado de acciones al de CDS aumenta considerablemente desde el estallido de la crisis financiera. ${ }^{3}$

Por otro lado, Kalbaska y Gatkowski (2012) estudian las correlaciones e interdependencias entre los mercados de CDS soberanos de los países denominados PIIGS con Francia y Alemania, ya que estos dos últimos son los que más deuda pública adquirieron de los países anteriores. Como conclusión se expone que las interconexiones se han incrementado desde el estallido de la crisis subprime y además se señala que dentro de los PIIGS, los mercados de CDS de España e Irlanda han tenido mayor impacto sobre el mercado de CDS Europeo, mientras que Portugal es el país más vulnerable a los distintos shocks que se puedan originar.

Alter y Schüler (2012) analizan las interconexiones entre los mercados de CDS soberanos y bancarios de ciertos países de la Eurozona (Alemania, España, Francia, Holanda, Italia, Irlanda y Portugal) entre 2007 y 2010, concluyendo que el efecto contagio del mercado de CDS soberanos sobre el mercado de CDS bancarios se ha intensificado a raíz de los rescates financieros. Además, también se señala que los shocks a corto plazo sobre los CDS bancarios afectan con una mayor intensidad a los CDS soberanos después de los rescates y, en cambio, los shocks a largo plazo carecen de relevancia. ${ }^{4}$

Dada la importancia que tiene conocer la dirección de los flujos de información existentes entre las entidades financieras, en este trabajo analizamos la transmisión del riesgo de crédito exclusivamente en el sector bancario europeo, intentando dar respuesta a diversas cuestiones. En primer lugar, estudiamos la existencia de evidencia de transmisión del riesgo de crédito entre las entidades financieras europeas distinguiendo entre si pertenecen o no a la Eurozona. A continuación nos preguntamos si dicha transmisión es bidireccional o unidireccional, concretamente para conocer qué países han liderado dicha transmisión. Por último, analizamos en qué medida las recientes crisis financieras han afectado a la transmisión del riesgo de crédito previamente estudiada. El objetivo del presente trabajo es dar respuesta a dichas cuestiones contribuyendo de manera significativa a la literatura reciente.

A partir de 2008, el mercado de CDS ha cobrado mucha importancia y son considerados actualmente una buena aproximación de la probabilidad de quiebra de la entidad de referencia y por tanto del nivel de riesgo asumido por la contraparte. Por ello, como viene siendo habitual en la literatura, consideramos como proxy del riesgo de crédito de una determinada entidad su CDS spread. ${ }^{5}$ Estos títulos reflejan, además, la percepción del mercado acerca de la salud financiera de las entidades bancarias, por lo que son buenos indicativos de la estabilidad financiera. Además, hoy en día son los productos derivados más líquidos y representan aproximadamente la mitad de los derivados de crédito negociados en dicho mercado.

La transmisión de riesgo de crédito se analiza tanto a nivel de zona monetaria como a nivel de país, entre los países pertenecientes a la Eurozona (recogidos en la cartera Euro) respecto a los que no pertenecen a la unión monetaria (cartera No Euro). Para ello se han estimado modelos VAR (vector autorregresive) utilizando el concepto de causalidad en el sentido de Granger. Además, se analizan las funciones impulso-respuesta de las zonas monetarias para observar durante cuánto tiempo persiste un shock introducido en el sistema y cuál es su influencia en el resto de variables. 
El amplio periodo muestral comprendido entre Enero de 2006 y Marzo de 2012 nos permite estudiar el comportamiento de la transmisión del riesgo de crédito tanto en periodos de estabilidad como inestabilidad financiera, lo que resulta de vital importancia dadas las gravísimas consecuencias que ha tenido para los países de la Eurozona las recientes crisis financieras. En concreto, siguiendo a Drudi, Durré, y Mongelli (2012) la muestra se ha dividido en un primer sub-periodo de relativa tranquilidad hasta el 9 de Agosto 2007, cuando los efectos de la crisis subprime comenzaron a ser más que evidentes en Europa, y dos sub-periodos de inestabilidad financiera, la crisis financiera global y la consecuente crisis de deuda soberana de la Eurozona, a partir del 8 de Mayo 2010, fecha en la que se aprobó el primer rescate a Grecia.

Hasta lo que conocemos, éste es el primer trabajo que estudia en profundidad las vías de transmisión del riesgo de crédito bancario utilizando los CDS spreads exclusivamente para el sector bancario europeo. Además, se analizan estas interconexiones de crédito tanto a nivel de zona monetaria como a nivel de país. Finalmente, se identifican dos eventos críticos recientes que caracterizan el inicio de las recientes crisis financieras para medir las diferencias en la transmisión de riesgo de crédito entre los periodos pre y post evento con el objetivo de observar cómo han evolucionado las relaciones de causalidad entre países y zonas después de dichos eventos significativos.

Los resultados obtenidos sugieren que la transmisión del riesgo de crédito en las entidades bancarias europeas ha cambiado con las distintas crisis financieras analizadas tanto en intensidad como en la dirección de las interrelaciones. Mientras que en periodos de estabilidad financiera las relaciones de causalidad son casi inexistentes, éstas aumentaron con el inicio de la crisis subprime y se hicieron más evidentes con la crisis de deuda soberana en la Eurozona. Respecto a la dirección en estos dos episodios de crisis, encontramos que la transmisión del riesgo de crédito se origina desde las entidades de la Eurozona hacia las entidades que no pertenecen a dicha zona. Además, los shocks originados en el riesgo de crédito de las entidades bancarias de la Eurozona tienen un efecto notable a muy corto plazo en los bancos de la zona No Euro, con una mayor intensidad desde la crisis subprime hasta la actualidad. El análisis por países confirma que son los bancos de la Eurozona los que lideran la transmisión del riesgo de crédito. Ésta se intensifica a raíz del primer rescate griego sobre todo en lo que a relaciones unidireccionales se refiere provenientes de entidades financieras de los países periféricos del sur de la Eurozona, lo que no es de extrañar si tenemos en cuenta que éstos fueron precisamente los más castigados por la crisis de deuda soberana que caracterizó este último periodo.

El resto del trabajo queda estructurado del siguiente modo. En la sección 2 se lleva a cabo una exposición detallada de los datos utilizados en el estudio. La sección 3 describe la metodología aplicada, mientras que la sección 4 presenta los resultados obtenidos en el análisis empírico. Por último, la sección 5 recoge las conclusiones más relevantes.

\section{Datos}

\subsection{Descripcion}

La muestra consiste en datos de CDS spreads diarios de las principales entidades financieras europeas, ${ }^{6}$ obtenidos de la base de datos Thomson Datastream, concretamente de CMA New York. ${ }^{7}$ El CDS spread muestra la prima media periódica (premium mid spread) expresada en puntos básicos, es decir, la media aritmética entre los CDS spreads ofertados (premium bid spread) y demandados (premium ask spread) por un grupo de 
contribuyentes $^{8}$ que reportan sus precios diariamente a CMA. ${ }^{9}$ Utilizamos los CDS spreads de vencimiento a cinco años puesto que estos contratos son generalmente considerados los más líquidos y constituyen el vencimiento más negociado [véase Blanco, Brennan, y Marsh (2005) y Coudert y Gex (2013) entre otros].

El periodo muestral abarca desde Enero de 2006 hasta Marzo de 2012, lo que permite investigar en profundidad dos eventos que pueden haber tenido un impacto diferente en el mercado de CDS: el comienzo de la crisis financiera global con el estallido de la crisis subprime (9 de Agosto de 2007), CS a partir de ahora, ${ }^{10}$ y el primer rescate a Grecia, que constituye el inicio de la crisis de deuda soberana en Europa (8 de Mayo de 2010), DS a partir de ahora. Para analizar de manera independiente las relaciones de causalidad que se han producido antes y después de cada uno de los dos eventos, la muestra total ha sido dividida en tres subperiodos, cubriendo los periodos anteriores y posteriores a los eventos. ${ }^{11}$ Los tres subperiodos van a ser denominados de la siguiente manera: SP1 (2 de Enero de 2006 - 8 de Agosto de 2007), SP2 (9 de Agosto de 2007 - 7 de Mayo de 2010) y SP3 (8 de Mayo 2010 - 26 de Marzo de 2012).

Las entidades bancarias utilizadas han sido seleccionadas atendiendo a la disponibilidad de entidades que negocian CDS incluidas dentro de la base de datos, lo que hace un total de 69.873 observaciones de panel (no balanceadas) que incluyen un total de 45 bancos en 14 países europeos en 1.626 días. Se dispone por tanto del $90 \%$ de los bancos europeos que negocian CDS. ${ }^{12}$ El Apéndice A muestra la lista de bancos incluidos en la muestra y para cada banco, el número de observaciones disponibles, así como el valor de activo total a Diciembre de $2011^{13}$ obtenido del balance de cada entidad.

Dado que el objetivo principal del trabajo es analizar las relaciones de causalidad entre los CDS de las entidades bancarias europeas distinguiendo por zona monetaria, se han formado carteras equiponderadas de CDS clasificando las entidades bancarias por países, y a continuación, formando dos carteras (Euro y No Euro) atendiendo a si los países pertenecen o no la Eurozona. ${ }^{14}$ La cartera Euro está formada por Alemania, Austria, Bélgica, España, Francia, Grecia, Holanda, Italia y Portugal. La cartera No Euro está construida usando datos de Dinamarca, Noruega, Suecia, Suiza y Reino Unido, países europeos fuera de la Eurozona. ${ }^{15}$ La idea de construir carteras equiponderadas corresponde al hecho de crear una cartera de CDS que recoja el riesgo de crédito medio de los bancos de un país o de una determinada zona monetaria. ${ }^{16}$

La Figura 1 muestra la evolución temporal diaria de los CDS spreads, tanto a nivel de zona monetaria (carteras Euro y No Euro), como a nivel país. Los estadísticos descriptivos más importantes se encuentran en la Tabla 1.

En el SP1, los spreads de los CDS se mantuvieron relativamente estables para todos los países, siendo la cartera No Euro la que presenta el nivel medio más bajo, alrededor de $9 \mathrm{pb}$, frente a los $14 \mathrm{pb}$ de la cartera Euro, que además presenta el doble de volatilidad, mientras que el resto de países presentan en general valores muy bajos de volatilidad.

El estallido de la crisis subprime tuvo un efecto relevante en los CDS europeos. Durante el periodo SP2 los niveles de estos derivados financieros crecieron significativamente en ambas carteras hasta alcanzar valores medios de $120 \mathrm{pb}$ en la cartera Euro y $88 \mathrm{pb}$ en la No Euro, lo que supuso un incremento espectacular del $750 \%$ y $920 \%$, respectivamente, en relación al nivel medio de la etapa anterior. Todos los países experimentaron un incremento progresivo y pronunciado hasta Marzo de 2009, lo que provocó que las volatilidades se dispararan en este segundo subperiodo. A partir de esta fecha los spreads decrecieron, debido en gran parte a las ayudas y medidas tomadas en forma de avales para la banca europea, y se estabilizaron, aunque en niveles superiores a 

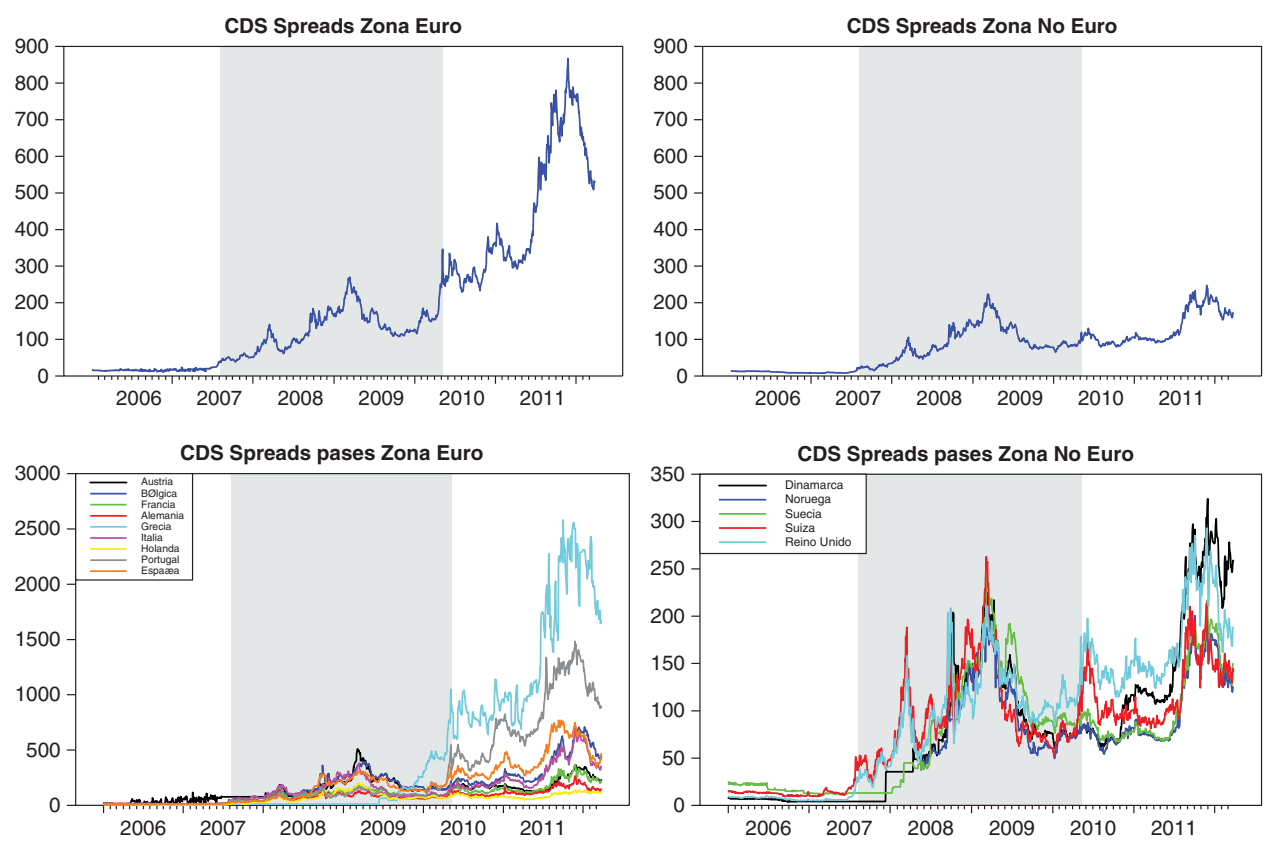

Figura 1. Evolución temporal de los CDS spreads bancarios.

La siguiente figura muestra la evolución temporal diaria de los CDS spreads (Panel A), tanto para las carteras por zonas Euro y No Euro como para todos los países individualmente. El periodo muestral comprende desde Enero de 2006 a Marzo de 2012. La zona sombreada en gris de los gráficos identifica dos eventos, crisis subprime (9 de Agosto de 2007), CS y el primer rescate a Grecia que constituye el inicio de la crisis de deuda soberana en Europa (8 de Mayo de 2010), DS, que dividen la muestra en tres sub-periodos.

los observados en la etapa anterior. Los bancos europeos tenían en su propiedad cantidades considerables de deuda soberana y en consecuencia la preocupación sobre la solvencia de los sistemas bancarios europeos se intensificó, al tiempo que crecía el miedo a una crisis de deuda soberana que no tardaría en producirse. La CS azotó notablemente a Europa en su conjunto, pero en mayor medida a los países de la zona Euro, siendo Alemania, Francia y Holanda los menos afectados, con valores de spreads medios y volatilidad menores y similares a los observados en los países de la zona No Euro. Por el contrario, cabe destacar el caso griego con una variabilidad de los CDS spreads máxima debida al espectacular valor de $1.050 \mathrm{pb}$ alcanzado. Después del primer rescate a Grecia por parte del FMI y de los socios de la Eurozona en Mayo de 2010, DS, y a pesar de que se produjo un aumento de los niveles de los CDS en las dos carteras por zona, se pueden observar diferencias significativas entre la evolución de las mismas. Mientras que los precios de los derivados financieros de los países de la zona No Euro sufrieron un incremento medio del $49 \%$ y se mantuvieron estables durante la mayor parte del periodo SP3, los estados de la zona Euro vieron crecer sus CDS spreads de forma más notoria, alrededor de un $253 \%$ en media. Esta diferencia, se debe principalmente a que ciertos países de la zona Euro sufrieron incrementos espectaculares en los CDS respecto a la etapa anterior. Los casos más destacados fueron Grecia $(1.352 \%$, con un máximo de $2.586 \mathrm{pb}$ en Octubre de 2011), Portugal (672\%, con un máximo de 1.484 pb en Noviembre 2011), España (187\%) e Italia (112\%). Estas economías han sido las 


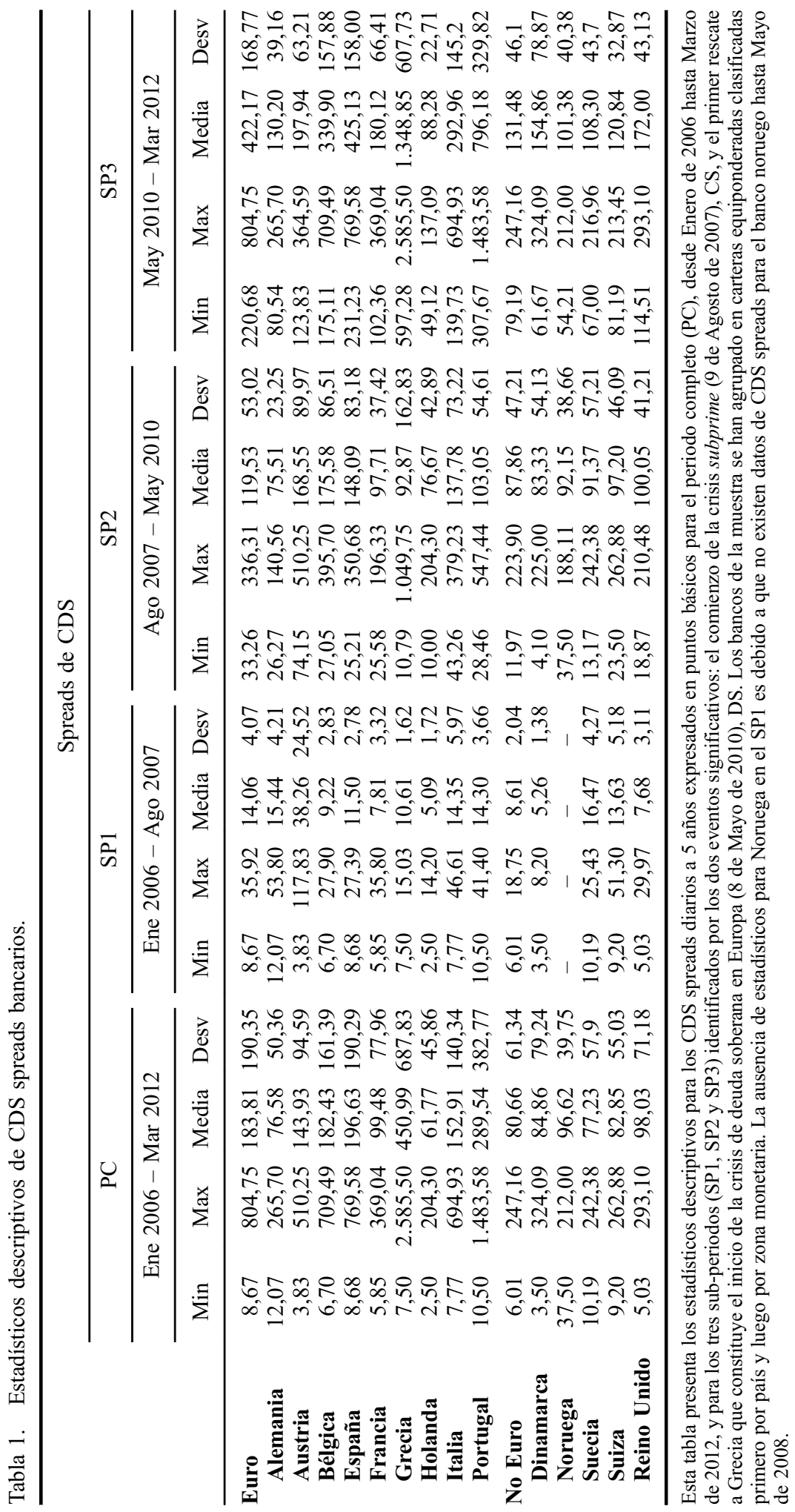


que más directamente se han visto afectadas por la crisis de la deuda soberana ya que el primer rescate griego hizo aparecer muchas dudas entre los inversores sobre la capacidad de hacer frente a las deudas por parte de los estados con mayores dificultades. Esta falta de confianza se extendió sobre todo a los países de la Eurozona con mayor déficit público, y en consecuencia los inversores aumentaron considerablemente su percepción del riesgo de crédito (riesgo país). De este modo, el coste de financiación de los estados aumentó, y se extendió rápidamente a los bancos en gran parte debido a la elevada cantidad de deuda pública que dichas entidades tienen en su propiedad, con lo que el problema se agravó y los niveles de los CDS bancarios sufrieron un fuerte incremento. Por el contrario, los países de la zona Euro no periféricos, como Francia (180 pb), Alemania (130 pb) y Holanda (88 pb) presentaron valores medios mucho menores y similares a los de la zona No Euro. En consecuencia, la desviación típica de la cartera Euro fue cuatro veces superior a la de la cartera No Euro, debido a la gran variabilidad observada en los países con problemas de deuda soberana.

\subsection{Analisis estadistico preliminar}

Siguiendo a Forte y Peña (2009) y a Kalbaska y Gatkowski (2012) entre otros, en primer lugar se han transformado los CDS spreads diarios calculando diferencias logarítmicas con el objetivo de obtener series estacionarias, es decir, tomando la diferencia entre el logaritmo del CDS spread del día $t$ menos el logaritmo del CDS spread del día $t-1$ para cada una de las entidades bancarias de la muestra:

$$
C D S_{t}=\log \left(C D S \text { spread }_{t}\right)-\log \left(C D S \text { spread }_{t-1}\right)
$$

De esta manera, la serie resultante, denominada de aquí en adelante como CDS, recoge la variación relativa producida en el riesgo de crédito. ${ }^{17}$

La Tabla 2 presenta varios contrastes estadísticos para los CDS de las carteras Euro y No Euro, así como para los países que las integran. El contraste de Jarque-Bera rechaza, independientemente del subperiodo, la normalidad de todas las series, debido al exceso de curtosis y a la asimetría (Panel A). Estos resultados son indicativos de distribuciones no normales y de colas anchas, que son características comunes en las series financieras. El test de Ljung-Box (Panel B) revela que en general existe autocorrelación en media tanto en el periodo completo como en los distintos subperiodos, por lo que existe persistencia en media. Por último, ambos test Dickey y Fuller (1981) Aumentado (ADF) y Phillips y Perron (1988) (PP) (Panel B) rechazan la hipótesis nula de existencia de raíz unitaria de todas las series, por lo que éstas son estacionarias. Estos resultados justifican la utilización posterior de un modelo VAR para estudiar la causalidad existente entre las series de CDS de las distintas zonas monetarias y países.

El Panel C muestra la matriz de correlaciones entre los CDS de cada zona y país. Para el periodo completo (Panel C.1) destaca en primer lugar la alta correlación $(0,81)$ observada entre las carteras Euro y No Euro. Los países de la zona No Euro más correlacionados con la cartera Euro son Suiza y Reino Unido (en torno a 0,80), mientras que Francia, Alemania, Italia y Holanda son los países de la zona Euro que más influyen (con valores en torno a 0,75) en la evolución de la cartera No Euro. Las correlaciones más altas entre países de distintas zonas se dan entre Suiza y Reino Unido con Alemania, Francia e Italia (con correlaciones en torno 0,80), y, en menor medida, con Holanda, Portugal y España (con correlaciones entre 0,60 y 0,70). Finalmente, destaca el 


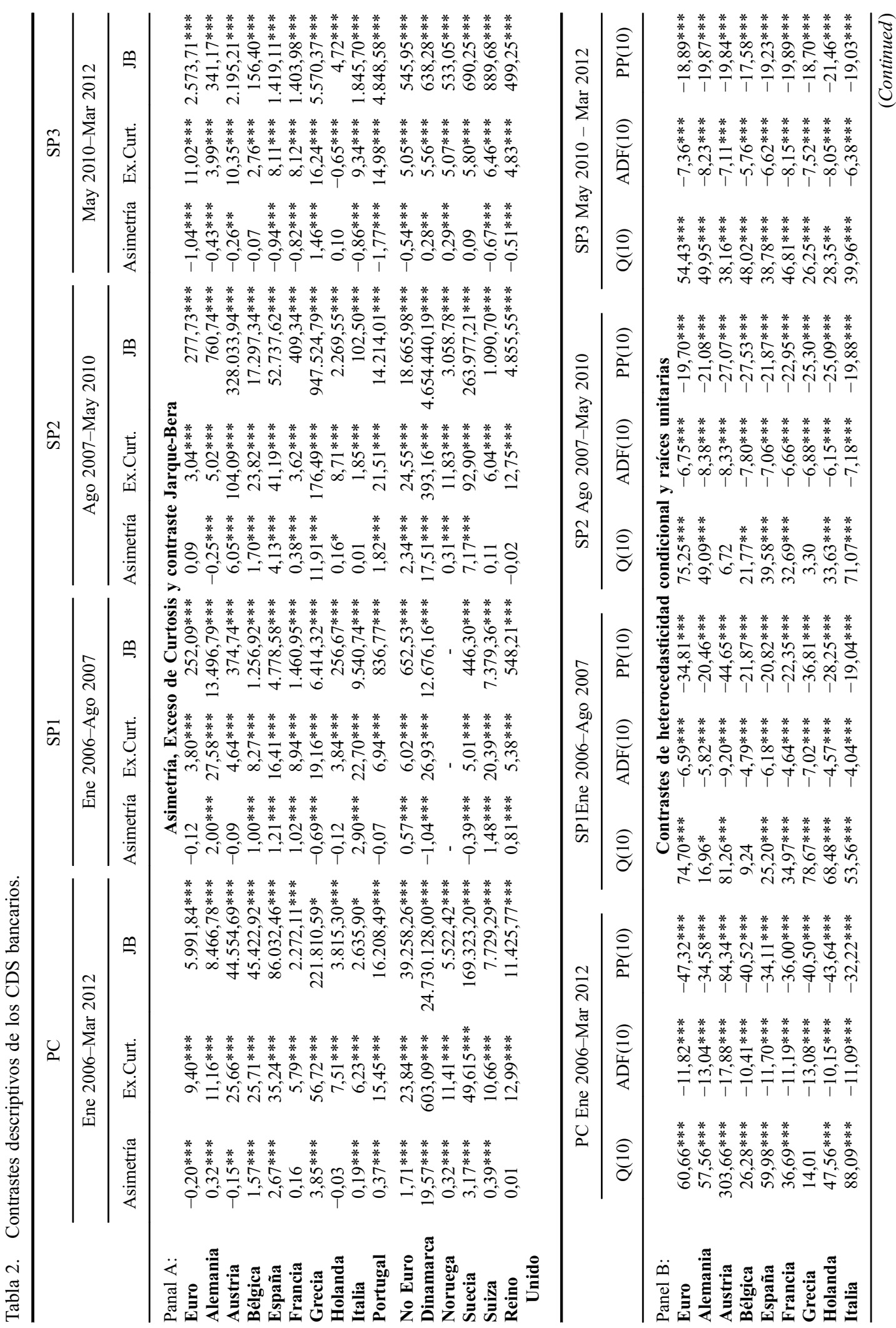




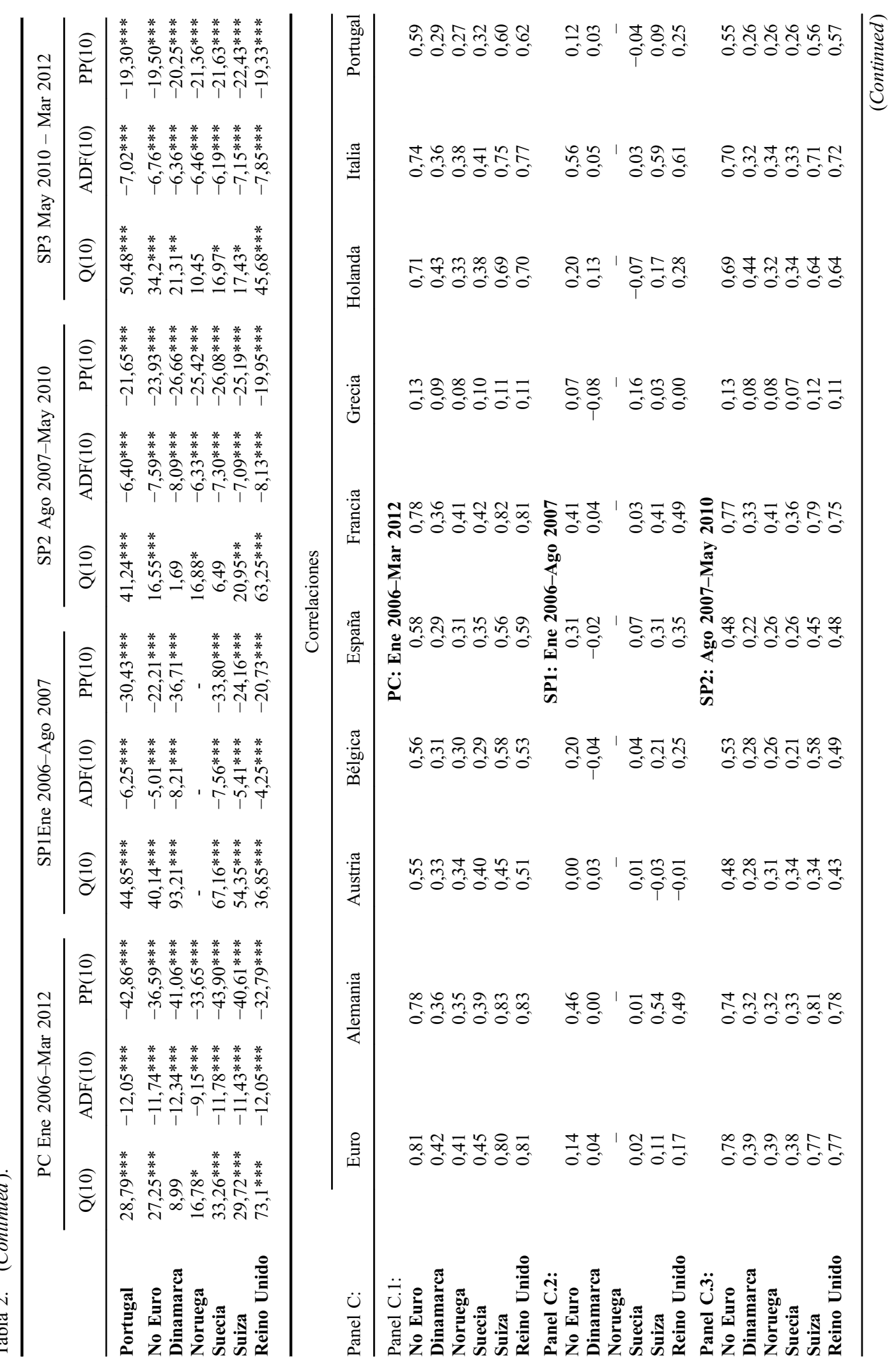




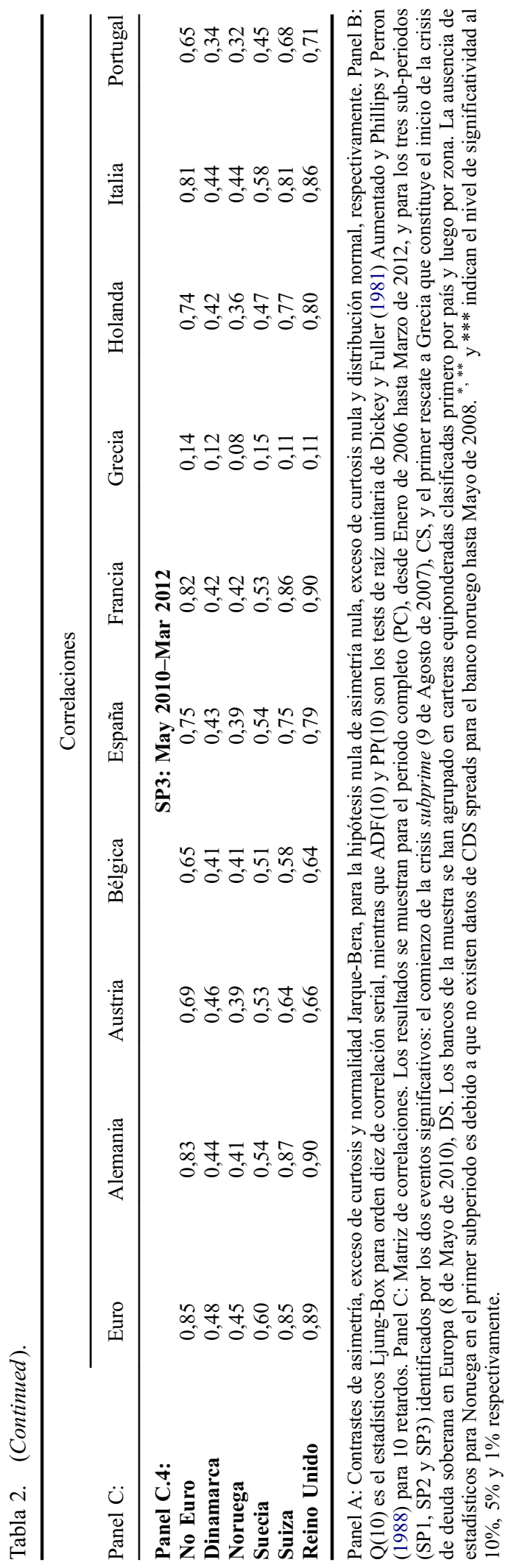


caso griego, ya que con correlaciones muy bajas presenta un comportamiento dispar al resto.

Un análisis más detallado de las correlaciones por subperiodos deja de manifiesto la evolución de las relaciones existentes en el riesgo de crédito bancario existente entre las distintas zonas y países. Destaca la ausencia de correlaciones durante el periodo de mayor estabilidad (SP1, Panel C.2). La relación entre las dos zonas monetarias consideradas es prácticamente inexistente $(0,14)$. Los distintos países de la zona No Euro no presentan relación con la cartera Euro. Sin embargo, se observa una correlación relativamente alta de la cartera No Euro con Italia $(0,56)$, Alemania $(0,46)$ y Francia $(0,41)$, que es debido a la correlación existente entre estos países y Suiza y Reino Unido (con valores entre 0,50 y 0,60 ).

Con la CS (Panel C.3) las correlaciones se disparan. La correlación entre zonas pasa del 0,14 al 0,78 después de la crisis. Destacan sobre todo los altos valores observados para Reino Unido y Suiza con respecto a la cartera Euro $(0,77)$, así como para Francia, Alemania, Italia y Holanda con respecto a la cartera No Euro (en torno a 0,70 y superiores). Entre países, son de nuevo Suiza y Reino Unido con Alemania, Francia e Italia las que presentan una mayor correlación (en torno a 0,70 y 0,80 ), aunque el aumento es general.

Con la DS (Panel C.4) las correlaciones siguieron aumentando aunque con menor intensidad. La correlación entre zonas aumentó hasta 0,85 , siendo de nuevo Reino Unido y Suiza los países más correlacionados con la cartera Euro (con valores cercanos al 0,90), y Alemania, Francia e Italia y en este tercer subperiodo también España (con un incremento considerable) con la cartera No Euro (con valores en torno a 0,80 ). A nivel de país, son los países mencionados, Suiza y Reino Unido (de la zona No Euro) con respecto a Alemania, Francia, Italia, España, así como Portugal (de la zona Euro) los que presentan una mayor correlación (en general mayor que 0,80). Por otro lado, es notable el incremento de correlaciones experimentado con respecto al subperiodo anterior en el caso de los países del sur de Europa, en particular, España, Italia y Portugal, lo que puede atribuirse a los problemas de deuda soberana que estos países estaban atravesando. Cabe destacar el caso de Grecia, cuyas correlaciones con el resto de series se han mantenido muy bajas a lo largo de todo el período muestral, incluso en SP3, periodo caracterizado por la crisis de deuda soberana de la Eurozona, en concreto de los países del sur de Europa y en mayor medida en Grecia. Estos resultados son indicativos de la particularidad del caso griego que parece presentar una evolución dispar al resto. Aunque la grave situación de Grecia originó la crisis de deuda soberana Europea, y en concreto, la crisis de los países periféricos España, Italia y Portugal, el deterioro experimentado por Grecia ha sido mucho más acusado (véase la Figura 1), lo que explica una menor correlación de Grecia con el resto de países.

\section{Metodologia}

\subsection{Casusalidad en el Sentido de Granger}

Siguiendo el concepto de causalidad de Granger (1969) se considera en primer lugar un modelo vectorial autorregresivo $\mathrm{VAR}^{18}$ que viene dado por las siguientes ecuaciones:

$$
C D S_{t}^{x}=\alpha_{1}+\sum_{j=1}^{p} \beta_{1, j}^{y} C D S_{t-j}^{y}+\sum_{j=1}^{p} \gamma_{1, j}^{x} C D S_{t-j}^{x}+u_{1, t}
$$




$$
C D S_{t}^{y}=\alpha_{2}+\sum_{j=1}^{p} \beta_{2, j}^{y} C D S_{t-j}^{y}+\sum_{j=1}^{p} \gamma_{2, j}^{x} C D S_{t-j}^{x}+u_{2, t}
$$

donde $C D S_{t}^{x}$ y $C D S_{t}^{y}$ son las dos series de CDS consideradas para las carteras $x$ e $y, \alpha_{i}, \beta_{i, j}^{y}$ y $\gamma_{i, j}^{x}$ representan los coeficientes estimados por el método de mínimos cuadrados ordinarios y $u_{i, t}$ son los términos de error del modelo $(i=1,2)$. La elección del número óptimo de retardos $p$ del VAR se realiza siguiendo los criterios de información de Akaike (AIC) y el ratio de verosimilitud (LR). En general existe consistencia entre ambos criterios, pero en caso contrario se ha utilizado el orden sugerido por LR para evitar la sobreparametrización.

A continuación se contrasta si la serie $C D S_{t}^{y}$ no causa en el sentido de Granger a la serie $C D S_{t}^{x}$, de manera que la hipótesis nula es la siguiente

$$
H_{0}=\beta_{1,1}^{y}=\ldots=\beta_{1, p}^{y}=0
$$

y por tanto, la causalidad de $C D S_{t}^{y}$ a $C D S_{t}^{x}$ viene dada si se rechaza la nulidad conjunta de todos los coeficientes $\beta_{1}^{y}$, de la ecuación (2) (es decir, si alguno es no nulo).

Análogamente, de la ecuación (3), se contrasta si la serie $C D S_{t}^{x}$ no causa en el sentido de Granger a la serie $C D S_{t}^{y}$, donde la hipótesis nula viene dada por

$$
H_{0}=\gamma_{2,1}^{x}=\ldots=\gamma_{2, p}^{x}=0
$$

y por tanto, la causalidad de $C D S_{t}^{x}$ a $C D S_{t}^{y}$ viene dada si se rechaza la nulidad conjunta de todos los coeficientes $\gamma_{2}^{x}$, de la ecuación (3) (es decir, si alguno es no nulo).

Para ello se utiliza la significatividad del estadístico $F$ obtenido al comparar el modelo general dado por las ecuaciones (2) y (3), con el modelo restringido, dado por la hipótesis nula (4) y (5), respectivamente, y que viene dado por la siguiente expresión

$$
G=\frac{\left(S C E_{R}-S C \cdot E_{G}\right)(T-2 \cdot p-1)}{p \cdot S C E_{G}} \sim F(p, T-2 \cdot p-1)
$$

donde $S C E_{R}\left(S C E_{G}\right)$ es la suma de cuadrados residual del modelo restringido (general), $T$ el tamaño muestral y $p$ el número de retardos óptimo del modelo VAR . Básicamente se contrasta si la inclusión de variables adicionales al modelo restringido mejora significativamente la explicación de las relaciones existentes entre las series consideradas.

\subsection{Funciones impulso-respuesta}

Las funciones impulso-respuesta muestran la reacción de las variables del sistema planteado ante cambios en los errores del mismo. Se analiza durante cuánto tiempo persiste un shock introducido en el sistema y cuál es su influencia en el resto de variables que no han sido afectadas directamente por dicho shock.

Las innovaciones de las ecuaciones (2) y (3) son no ortogonales, puesto que en general la matriz de covarianza $\sum^{=} E\left(u_{t} u_{t}^{\prime}\right)$ no es diagonal. Por esta razón, es mucho más apropiado observar la representación de la media móvil con las innovaciones ortogonalizadas. Si escogemos cualquier matriz $G$ que cumpla $G \sum^{G}=I$, las nuevas innovaciones 
$\varepsilon_{t}=G u_{t}$ satisfacen $E\left(\varepsilon_{t}, \varepsilon_{t}^{\prime}\right)=I$ y tienen la propiedad de que están incorrelacionadas en el tiempo y entre ecuaciones. Para realizar la ortogonalización, se ha seguido el método de descomposición estructural, frecuentemente conocido como SVARS, propuesto por Bernanke (1986) y Sims (1986) obteniendo las funciones impulso-respuesta generalizadas (GIRF), ${ }^{19}$ planteadas por Pesaran y Shin (1998).

Hay que tener en cuenta que un shock en $\varepsilon_{1, t}$ afectará directamente a $C D S_{t}^{x}$, pero también puede modificar los CDS futuros de las dos series $x$ e $y$. Esto se debe a que las dos ecuaciones (2) y (3) contienen los retardos correspondientes a $C D S_{t}^{x}$. Por tanto, la función impulso-respuesta muestra el efecto de un cambio en los errores sobre los CDS actuales y futuros de la serie $x$, así como de los CDS futuros de la serie $y$. Un razonamiento análogo serviría para el caso de $\varepsilon_{2, t}$.

\section{Resultados}

Con el objetivo de analizar la transmisión del riesgo de crédito del sector bancario europeo, se analizan las relaciones de causalidad (tanto unidireccionales como bidireccionales) existentes entre las distintas series temporales, tanto a nivel de zona monetaria como a nivel de país entre las distintas zonas. Más concretamente, se estudia, en primer lugar, si la cartera Euro causa en el sentido de Granger a la cartera No Euro, es decir, si la primera aporta información estadísticamente significativa a la segunda, y en segundo lugar, si cada uno de los distintos países de la zona Euro causa en el sentido de Granger a cada uno de los países que no forman parte de dicha zona. Al mismo tiempo también se analiza si esta relación de causalidad se produce en sentido contrario o si es bidireccional.

La estimación se ha llevado a cabo para el periodo muestral completo, así como para los tres subperiodos descritos previamente en la sección de datos. Esta forma de proceder tiene por objeto analizar las relaciones de causalidad antes y después de dos eventos significativos: el comienzo de la crisis financiera global con el estallido de la crisis subprime (9 de Agosto de 2007), CS, y el primer rescate a Grecia, que constituye el inicio de la crisis de deuda soberana en Europa (8 de Mayo de 2010), DS.

\subsection{A nivel de zona monetaria}

La Tabla 3 muestra en el Panel A la existencia de una relación bidireccional en la causalidad de los CDS bancarios de las carteras Euro y No Euro, confirmando la existencia de una notable transmisión de riesgo de crédito entre las entidades financieras de ambas zonas para el periodo completo. Sin embargo, el análisis por subperiodos revela que dicha relación ha cambiado con los distintos eventos considerados dentro de un contexto de crisis financiera. Inicialmente (SP1), el test no encuentra evidencias de causalidad entre los CDS de ambas zonas, aunque a un nivel de significatividad del $10 \%$ sí se observa una relación de causalidad unidireccional de la cartera No Euro a la cartera Euro. Con el estallido de la crisis subprime y hasta el final del periodo muestral (en SP2 y SP3), esta causalidad cambia de sentido y son los CDS de la zona Euro los que causan a la zona No Euro. Este resultado confirma cómo a partir de Julio de 2007 la transferencia de riesgo de crédito en el sector bancario se origina (en media) desde las entidades bancarias de la Eurozona hacia las entidades bancarias que no pertenecen a dicha zona. No es de extrañar que el aumento observado 


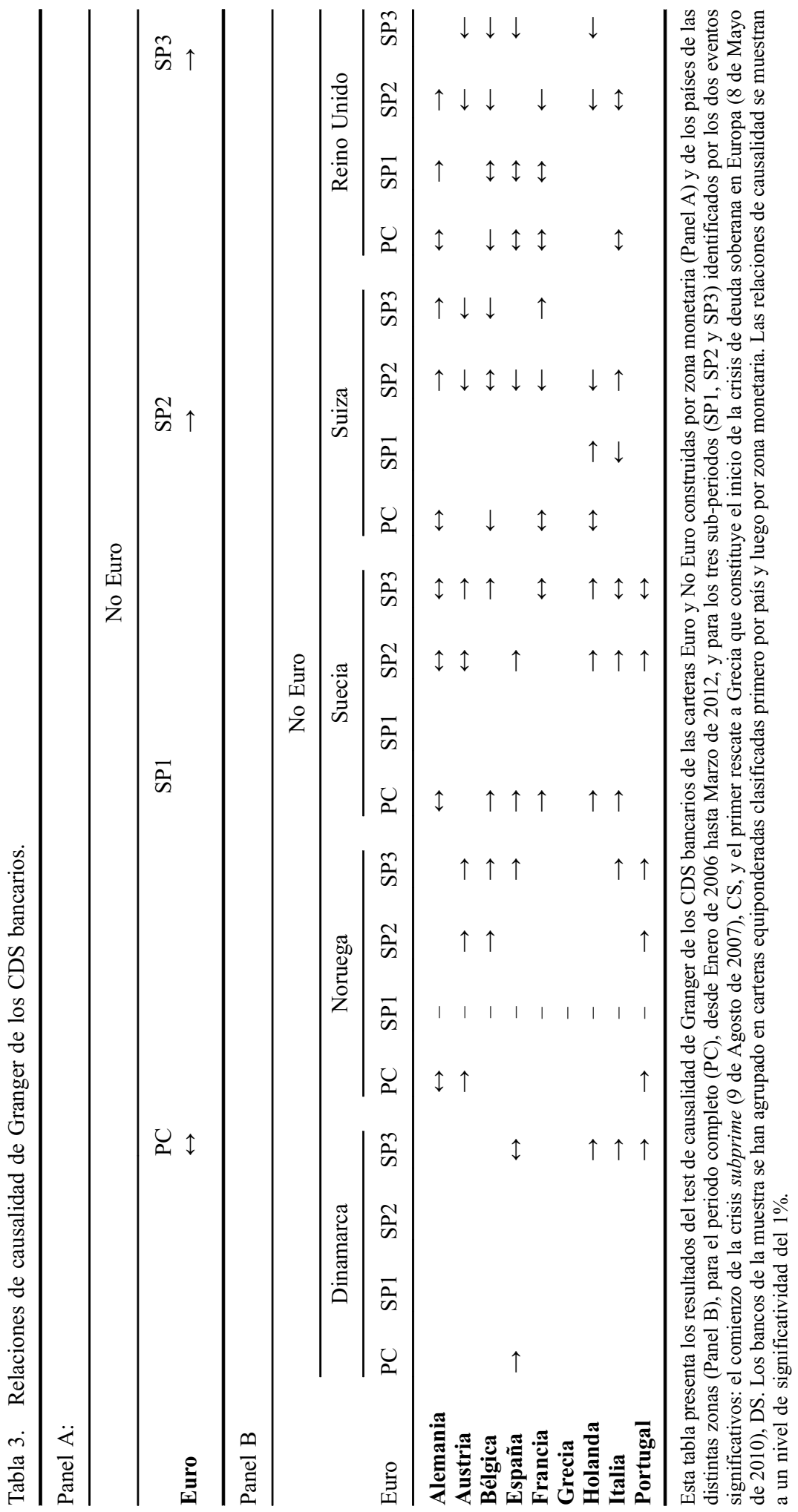


en las correlaciones durante los periodos de crisis venga acompañado de relaciones de causalidad más acusadas al pasar de un periodo de estabilidad financiera a un periodo de crisis.

Las funciones impulso-respuesta recogidas en la Figura 2 muestran que en general el efecto de los shocks en las carteras Euro y No Euro es a corto plazo, puesto que dura alrededor de 5 días y a partir de ahí desaparece. Además, independientemente del subperiodo, los CDS bancarios de la zona Euro se ven fuertemente afectados por sus propios shocks, con un impacto de $-38 \%$ (SP1), 30\% (SP2) y 33\% (SP3). Sin embargo, con valores de $-11 \%$ (SP1), $-4 \%$ (SP2) y $-10 \%$ (SP3), el impacto que los propios shocks tienen en los CDS de las entidades de la zona No Euro es mucho menos determinante.

Por otro lado, resulta interesante observar los efectos entre zonas que vienen a confirmar las relaciones de causalidad obtenidas previamente. Los shocks en la cartera de bancos de la zona No Euro tienen un notable efecto inmediato del $29 \%$ en la cartera Euro durante el periodo de estabilidad financiera SP1 (mientras que el efecto contrario es únicamente del 2\%). La situación cambia completamente con la crisis subprime. A partir de entonces y durante el periodo de crisis financiera global SP2 son los shocks en la cartera de bancos de la zona Euro los que tienen un fuerte impacto inmediato, del $23 \%$, en la cartera de bancos de la zona No Euro, que es aún mayor, del 33\% durante el periodo de crisis de la deuda soberana de la Eurozona SP3, aunque el efecto desaparece con mayor rapidez en ambos subperiodos (pasados dos días del shock el impacto es menor que el 10\%). Estos resultados sugieren que los shocks originados en el riesgo de crédito de las entidades bancarias de la Eurozona tienen un efecto notable a muy corto plazo en los bancos de la zona No Euro, con una mayor intensidad desde la crisis subprime hasta la actualidad.

Como análisis de robustez se ha calculado la descomposición de la varianza de los errores del modelo. Los resultados se muestran en la Tabla 4 y confirman lo obtenido previamente. Durante el primer subperiodo (SP1) la dependencia relativa entre ambas variables es casi inexistente, siendo prácticamente todo el porcentaje de la varianza del error de predicción debido a sus propias innovaciones. En cambio, con el inicio de la crisis (SP2) la varianza del error de los CDS bancarios de la zona Euro pasan a explicar alrededor del $50 \%$ de la varianza de los residuos de la cartera de la zona No Euro. En la última etapa (SP3), esta dependencia relativa se incrementó hasta el $68 \%$. De nuevo, es con el inicio de la crisis subprime cuando se observa la existencia de una transferencia del riesgo de crédito significativa de los bancos de la Eurozona hacia los bancos de la zona No Euro, más pronunciada durante la última parte del periodo muestral.

\subsection{A nivel de pais}

Un análisis de causalidad más detallado de las carteras de CDS bancarios por países revela interacciones interesantes entre los distintos componentes de las distintas zonas monetarias. El Panel B de la Tabla 3 muestra los resultados. Para el periodo completo destaca en primer lugar el caso de Grecia, cuya cartera de bancos no presenta ninguna relación causal con ninguna de las carteras bancarias de los países No Euro, a pesar de sus altos valores de CDS spreads. En cambio, los CDS bancarios de Suecia se ven influenciados por la práctica totalidad de los bancos de países de la zona Euro. Las relaciones de causalidad existentes para Suiza y Reino Unido son en general bidireccionales, con Alemania y Francia en ambos casos, y con Holanda, en el caso de Suiza, y España e Italia, en el caso de Reino Unido (con la excepción de que ambos países, Suiza 

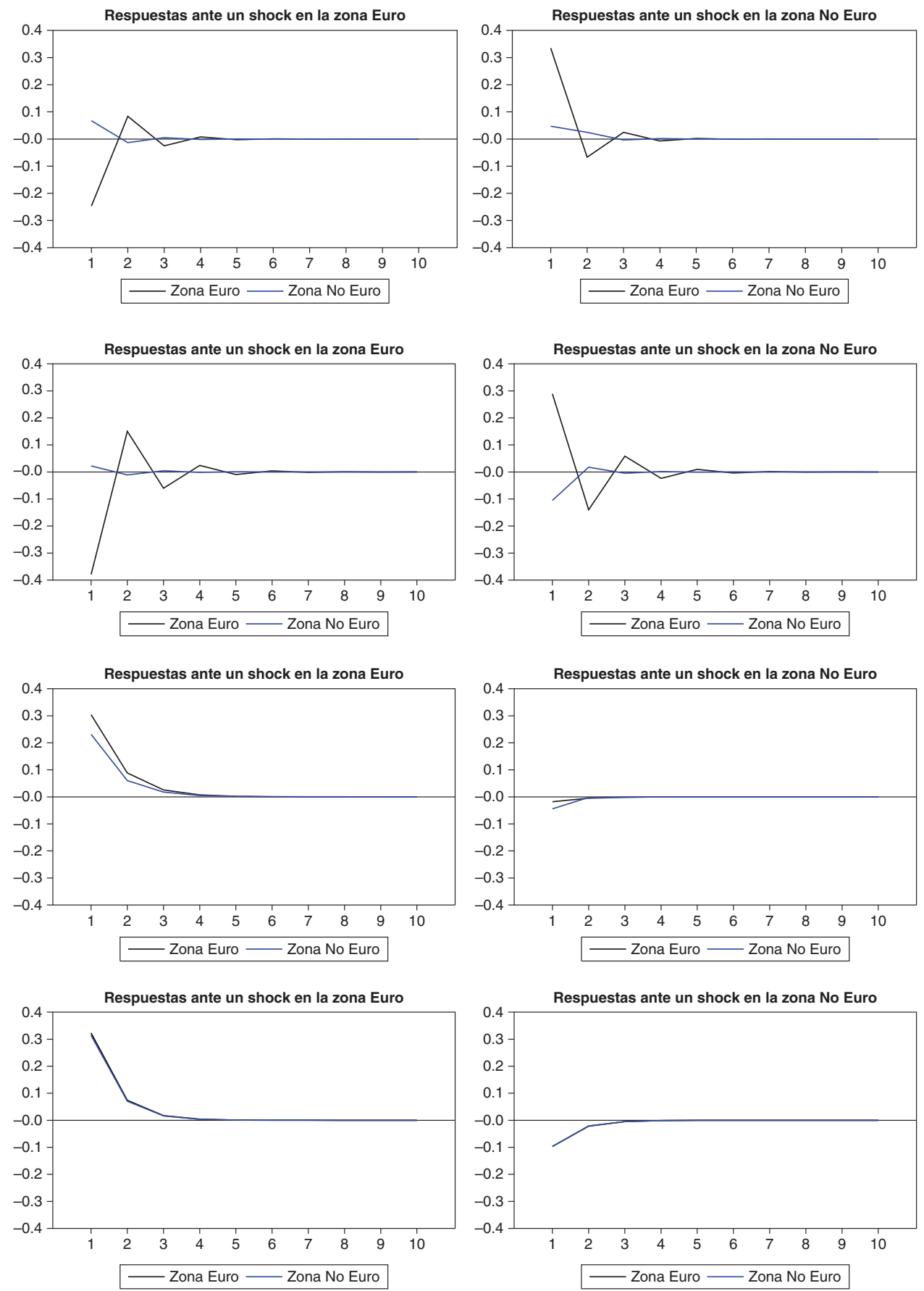

Figura 2. Funciones impulso respuesta.

La siguiente figura muestra las funciones impulso-respuesta para los CDS de las carteras Euro y No Euro construidas por zona monetaria, para el periodo completo (PC), desde Enero de 2006 hasta Marzo de 2012, y para los tres subperiodos (SP1, SP2 y SP3) identificados por los dos eventos significativos: el comienzo de la crisis subprime (9 de Agosto de 2007), CS y el primer rescate a Grecia que constituye el inicio de la crisis de deuda soberana en Europa (8 de Mayo de 2010), DS. 
Tabla 4. Descomposición de la varianza.

\begin{tabular}{|c|c|c|c|c|}
\hline \multirow[b]{2}{*}{ Día } & \multicolumn{2}{|c|}{ Panel A: Cartera Euro } & \multicolumn{2}{|c|}{ Panel B: Cartera No Euro } \\
\hline & Euro & No Euro & Euro & No Euro \\
\hline \multicolumn{5}{|c|}{ PC: Ene 2006-Mar 2012} \\
\hline 1 & 100,00 & 0,00 & 23,57 & 76,43 \\
\hline 2 & 96,30 & 3,70 & 24,66 & 75,34 \\
\hline 3 & 96,17 & 3,83 & 24,65 & 75,35 \\
\hline 4 & 96,16 & 3,84 & 24,66 & 75,34 \\
\hline 5 & 96,15 & 3,85 & 24,66 & 75,34 \\
\hline 6 & 96,15 & 3,85 & 24,66 & 75,34 \\
\hline 7 & 96,15 & 3,85 & 24,66 & 75,34 \\
\hline 8 & 96,15 & 3,85 & 24,66 & 75,34 \\
\hline 9 & 96,15 & 3,85 & 24,66 & 75,34 \\
\hline 10 & 96,15 & 3,85 & 24,66 & 75,34 \\
\hline \multicolumn{5}{|c|}{ SP2: Ago 2007-May 2010} \\
\hline 1 & 100,00 & 0,00 & 48,31 & 51,69 \\
\hline 2 & 99,98 & 0,02 & 49,88 & 50,12 \\
\hline 3 & 99,98 & 0,02 & 50,02 & 49,98 \\
\hline 4 & 99,98 & 0,02 & 50,03 & 49,97 \\
\hline 5 & 99,98 & 0,02 & 50,03 & 49,97 \\
\hline 6 & 99,98 & 0,02 & 50,03 & 49,97 \\
\hline 7 & 99,98 & 0,02 & 50,03 & 49,97 \\
\hline 8 & 99,98 & 0,02 & 50,03 & 49,97 \\
\hline 9 & 99,98 & 0,02 & 50,03 & 49,97 \\
\hline 10 & 99,98 & 0,02 & 50,03 & 49,97 \\
\hline \multicolumn{5}{|c|}{ SP1: Ene 2006-Ago 2007} \\
\hline 1 & 100,00 & 0,00 & 3,42 & 96,58 \\
\hline 2 & 99,33 & 0,67 & 3,65 & 96,35 \\
\hline 3 & 99,19 & 0,81 & 3,75 & 96,26 \\
\hline 4 & 99,17 & 0,84 & 3,76 & 96,24 \\
\hline 5 & 99,16 & 0,84 & 3,77 & 96,23 \\
\hline 6 & 99,16 & 0,84 & 3,77 & 96,23 \\
\hline 7 & 99,16 & 0,84 & 3,77 & 96,23 \\
\hline 8 & 99,16 & 0,84 & 3,77 & 96,23 \\
\hline 9 & 99,16 & 0,84 & 3,77 & 96,23 \\
\hline 10 & 99,16 & 0,84 & 3,77 & 96,23 \\
\hline \multicolumn{5}{|c|}{ SP3: May 2010-Mar 2012} \\
\hline 1 & 100,00 & 0,00 & 66,47 & 33,53 \\
\hline 2 & 99,70 & 0,30 & 67,99 & 32,01 \\
\hline 3 & 99,69 & 0,31 & 68,06 & 31,94 \\
\hline 4 & 99,69 & 0,31 & 68,07 & 31,93 \\
\hline 5 & 99,69 & 0,31 & 68,07 & 31,93 \\
\hline 6 & 99,69 & 0,31 & 68,07 & 31,93 \\
\hline 7 & 99,69 & 0,31 & 68,07 & 31,93 \\
\hline 8 & 99,69 & 0,31 & 68,07 & 31,93 \\
\hline 9 & 99,69 & 0,31 & 68,07 & 31,93 \\
\hline 10 & 99,69 & 0,31 & 68,07 & 31,93 \\
\hline
\end{tabular}

La siguiente tabla muestra la descomposición de la varianza (en porcentaje) del error para los CDS de las carteras Euro (Panel A) y No Euro (Panel B) construidas por zona monetaria, para el periodo completo (PC), desde Enero de 2006 hasta Marzo de 2012, y para los tres sub-periodos (SP1, SP2 y SP3) identificados por los dos eventos significativos: el comienzo de la crisis subprime (9 de Agosto de 2007), CS, y el primer rescate a Grecia que constituye el inicio de la crisis de deuda soberana en Europa (8 de Mayo de 2010), DS. 
y Reino Unido, afectan unidireccionalmente a Bélgica). Destaca también Alemania, con una relación de causalidad bidireccional con todos los países de la zona No Euro (salvo Dinamarca).

En cualquier caso, el análisis por subperiodos deja de manifiesto la necesidad de estudiar la evolución temporal de las relaciones de causalidad en el riesgo de crédito, ya que son evidentes los cambios producidos en dichas relaciones a lo largo del tiempo, así como la importancia del contexto global de crisis financiera de los últimos años, y en particular, de los dos eventos analizados, el inicio de la crisis subprime y el primer rescate a Grecia.

La Figura 3 recoge, únicamente por subperiodos, de manera más visual mediante diagramas, los resultados de la Tabla 3. Durante SP1, subperiodo caracterizado por su estabilidad financiera, la transmisión del riesgo de crédito bancario entre los países de las distintas zonas monetarias fue prácticamente inexistente. Únicamente destaca el caso del Reino Unido, con relaciones bidireccionales con Bélgica, Francia y España.

Tal y como cabría esperar, durante los subperiodos de fuerte inestabilidad financiera aumentaron de manera espectacular las relaciones de interdependencia (26 en total frente a las 6 de la etapa anterior), confirmando los resultados previos en relación a las correlaciones. En el SP2, entre los países de la zona No Euro las carteras de CDS bancarios de Suiza y Reino Unido presentan un comportamiento similar y confirman su importancia en la determinación de los CDS bancarios de la zona Euro. Por un lado, ambas carteras se vieron influenciadas por el riesgo de crédito de los bancos de Alemania, pero sobre todo influyeron de forma notable en las entidades bancarias de varios países centrales de la zona Euro, en concreto Francia, Austria, Holanda y en el caso de Reino Unido, también Bélgica. También destacan los casos de Noruega y Suecia cuyos CDS bancarios se vieron influenciadas por el riesgo de crédito de entidades de varios países de la zona Euro.

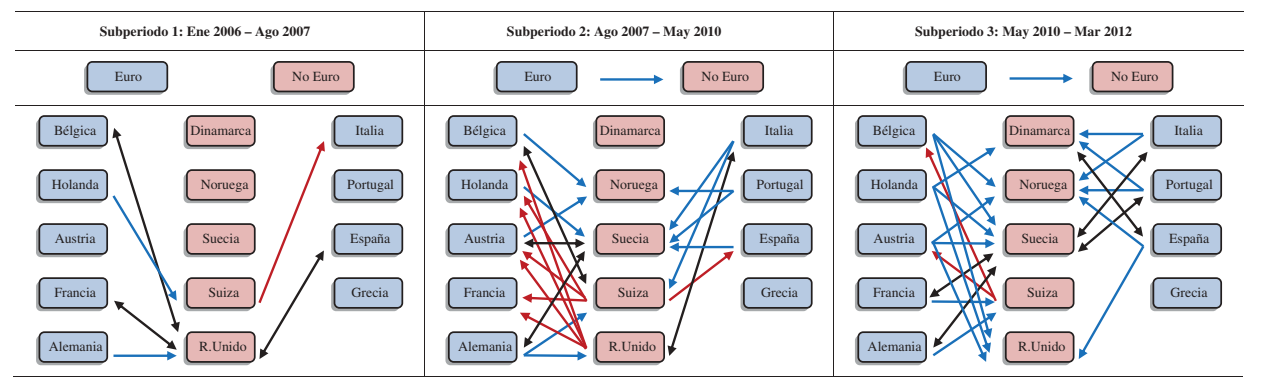

Figura 3. Relaciones de causalidad de Granger de los CDS bancarios.

La siguiente figura muestra los resultados obtenidos en el estudio en cuanto a relaciones de causalidad en sentido de Granger de los CDS bancarios de las carteras Euro y No Euro construidas por zona monetaria, así como de los países de las distintas zonas, para los tres subperiodos identificados por los dos eventos considerados, la crisis subprime (9 de Agosto de 2007), CS y el primer rescate a Grecia que constituye el inicio de la crisis de deuda soberana en Europa (8 de Mayo de 2010), DS. Las fechas en color azul (rojo) indican que la relación de causalidad es unidireccional de la zona Euro (No Euro) a la zona No Euro (Euro). Las fechas en color negro indican que la relación de causalidad es bidireccional. Las relaciones de causalidad se muestran a un nivel de significatividad del $1 \%$. 
Finalmente, en SP3, subperiodo posterior al primer rescate griego, se intensifica la transmisión de riesgo de crédito de los bancos de la zona Euro en los bancos de la zona No Euro, disminuyendo la influencia de la zona No Euro. Sólo Suiza mantiene su impacto únicamente sobre Austria y Bélgica, y se ve influenciado por el riesgo de crédito de Francia y Alemania. El Reino Unido recibe el impacto de Bélgica, Holanda, Austria y España. Por otro lado, los bancos de Suecia presentan relaciones bidireccionales con los bancos de Alemania, Francia, Italia y Portugal, además de verse influida por entidades de Bélgica, Holanda y Austria. Destaca a su vez el aumento de transferencias de riesgo de crédito, tanto bidireccionales como sobre todo unidireccionales, provenientes de entidades financieras de los llamados países periféricos de la zona Euro, Italia, Portugal y España, lo que no es de extrañar si tenemos en cuenta que estos fueron precisamente los países más castigados por la llamada crisis de deuda soberana de la Eurozona que caracterizó este último periodo. En este sentido, sorprende el caso de los bancos griegos, ya que a pesar de las dificultades en las que se vio inmersa Grecia, de su papel principal en dicha crisis y de sus altos niveles de CDS bancarios, ni siquiera durante el SP3 muestra transferencia de riesgo de crédito con el resto de entidades de países de la zona No Euro. Esto podría ser indicativo de un cierto aislamiento de la zona No Euro a la crisis de deuda soberana o al menos en lo que a los graves problemas acontecidos en Grecia. ${ }^{20}$

\section{Conclusiones}

El objetivo de este trabajo es estudiar en profundidad los canales de transmisión del riesgo de crédito, aproximado por los CDS spreads, entre las principales entidades bancarias europeas durante el periodo 2006-2012. La reciente crisis financiera global y la posterior crisis de deuda soberana en Europa ha dejado de manifiesto la vulnerabilidad de las entidades financieras europeas, evidenciando además la fragmentación existente entre los debilitados sectores bancarios de los países de la Eurozona y los que no pertenecen a ella. En este contexto, el estudio de la transmisión del riesgo de crédito de los bancos europeos se ha convertido en una cuestión primordial que preocupa tanto a reguladores y profesionales como a académicos. Sin embargo, esta cuestión ha recibido poca atención en la literatura reciente, a pesar de que el número de trabajos que estudian los mercados de CDS ha aumentado considerablemente en los últimos años.

El análisis se lleva a cabo utilizando el concepto de causalidad en el sentido de Granger, tanto a nivel de zona monetaria, como a nivel de país, entre las entidades bancarias pertenecientes a la Eurozona respecto a las que no pertenecen a ella, proporcionando evidencia adicional acerca de qué países han liderado dicha transmisión de riesgo de crédito. Además, el amplio periodo muestral nos permite analizar el comportamiento de dicha transmisión tanto en momentos de relativa estabilidad como inestabilidad financiera, así como su evolución en el tiempo.

Nuestros principales resultados sugieren un cambio en el comportamiento de la transmisión de los CDS bancarios de las zonas Euro y No Euro desde el inicio de la crisis subprime. En periodos de estabilidad financiera son los CDS bancarios de la zona No Euro los que causan débilmente a los de la zona Euro, mientras que a partir de Julio de 2007 (con la crisis financiera global) la transferencia de riesgo de crédito cambia de sentido originándose desde las entidades bancarias de la Eurozona hacia las que no pertenecen a dicha zona. Las funciones impulso respuesta confirman estos resultados. Un shock en el riesgo de crédito de los bancos de la zona Euro tiene un fuerte efecto a muy corto plazo en la zona No Euro. Desde la crisis subprime hasta la actualidad el efecto se intensifica a corto plazo, aunque el impacto se vuelve insignificante a largo plazo. 
El análisis detallado por países revela interrelaciones interesantes entre las entidades de las distintas zonas durante las recientes crisis financieras. Los bancos de varios países de la Eurozona se ven influenciados por el riesgo de crédito de los bancos de Suiza y Reino Unido. No obstante, son las entidades financieras de los países de la Eurozona las que lideran la transmisión del riesgo de crédito. Ésta se intensifica a raíz del primer rescate griego sobre todo en lo que a relaciones unidireccionales se refiere provenientes de entidades financieras de los países periféricos del sur de la Eurozona más castigados por problemas de deuda soberana (aunque el resto de países de la Eurozona son igualmente importantes). Destaca el aislamiento de los bancos griegos, puesto que a pesar de las dificultades en las que se vio inmersa Grecia y sus altos niveles de CDS bancarios, no muestran transferencia de riesgo de crédito con el resto de entidades de países de la zona No Euro.

Estos resultados pueden ayudar a entender los canales de transmisión del riesgo de crédito en momentos de turbulencia financiera y, por tanto pueden ser de gran utilidad en el diseño de los estándares de regulación bancaria con el objetivo de reducir la frecuencia e intensidad de futuras crisis sistémicas, así como la formulación de políticas monetarias adecuadas en Europa. Por último, nuestros resultados pueden servir de cara a diseñar estrategias de cobertura, diversificación y gestión de riesgos.

\section{Agradecimientos}

Los autores agradecen la financiación recibida de la Fundación Ramón Areces y A. GonzálezUrteaga de ECO2012-35946-C02-01 y ECO2012-34268. Los autores desean agradecer las sugerencias y comentarios recibidos por M. Paz Jordá, Ana María Ibáñez e Ignacio Martínez de Lejarza de la Universidad de Valencia. Autor de contacto: L. Ballester. Departamento de Economía Financiera y Actuarial, Facultad de Economía, Avda. dels Tarongers s/n, 46022, Valencia, España. Tel.: 9638283 69; Fax: 9638283 70. Laura.Ballester@uv.es

\section{Notes}

1. En enero de 2012 Standard \& Poor's baja los ratings de crédito de nueve países europeos, todos pertenecientes a la Eurozona. Francia y Austria pierden su rating AAA y pasan a tener una calificación de AA+, Italia y España bajan de grado dos niveles, mientras que la calificación de Portugal y Grecia se ve degradada a bono basura. Tan sólo, Alemania, Finlandia, Luxemburgo y Holanda mantienen la máxima nota de solvencia AAA.

2. González y Nave (2010) presentan, para el caso del mercado español, un análisis de eficiencia de las técnicas de medición del riesgo de mercado ante situaciones de crisis.

3. Existen otros trabajos como Fung, Sierra, Yau, y Zhang (2008) y Byström (2008) que estudian los comovimientos entre estos dos mercados con la familia de índices CDX e iTraxx, respectivamente. Norden y Weber (2009) introducen además en el estudio el mercado de bonos para analizar si dichos comovimientos son distintos con datos diarios o semanales.

4. En la misma línea, Acharya, Drechsler, y Schnabl (2011) encuentran evidencia empírica de contagio bidireccional entre ambos mercados, mientras que Ejsing y Lemke (2011), al analizar los movimientos conjuntos entre los mismos mercados para un periodo muestral menor, concluyen que los CDS bancarios decrecen a consecuencia de los rescates financieros a costa de aumentar los CDS soberanos, que son los más sensibles a shocks futuros.

5. El CDS es un derivado financiero que proporciona protección frente al riesgo de crédito de la entidad de referencia, y por tanto permite transferir el riesgo de impago. El comprador del producto obtiene el derecho a vender el subyacente por su valor nominal si ocurre el evento de impago, y al mismo tiempo el vendedor se compromete a adquirirlo. A cambio de dicha protección el comprador debe realizar pagos periódicos al vendedor hasta el final del contrato o hasta que se produzca el evento.

6. La decisión de seleccionar exclusivamente las entidades bancarias es debido principalmente al papel fundamental que han desempeñado en los periodos más recientes de inestabilidad 
financiera en Europa, así como por el rol histórico de intermediarios financieros que asumen en la economía. Son además los mayores usuarios de derivados de crédito y en particular, de CDS.

7. Mayordomo, Peña, y Schwartz (2014) concluyen que de las seis bases de datos de CDS más utilizadas, CMA es la base de datos que lidera a las demás.

8. Término comúnmente utilizado en el mercado de CDS para definir al conjunto de fuentes financieras que diariamente informan de los precios bid y ask de sus CDS spreads a CMA.

9. La periodicidad del CDS spread es trimestral y está establecida por convención internacional. Los pagos de la prima se realizan los 20 de junio, septiembre, diciembre y marzo de cada año.

10. La elección de los dos eventos se ha realizado siguiendo a Drudi et al. (2012). Aunque ya a partir de Julio de 2007 se percibieron varias señales de alarma en los mercados europeos, los efectos de la crisis subprime iniciada en EE.UU. comenzaron a ser más que evidentes en Europa a partir del 9 de Agosto de 2007, fecha en la que el banco francés BNP Paribas suspende temporalmente tres fondos ante la imposibilidad de calcular su valor liquidativo por la ausencia de precios de referencia.

11. Cada evento está incluido en el periodo post-evento.

12. La no inclusión del resto es debido a su negociación poco frecuente.

13. Tomamos como proxy del tamaño de las entidades bancarias el dato de activo total para el último año completo disponible.

14. La construcción de las carteras por zona atendiendo primero al país evita el problema de desequilibrio que surgiría si se tomaran carteras utilizando directamente los bancos de cada zona monetaria, debido al número tan variable de bancos disponibles en cada país.

15. Se incluyen todos los países europeos fuera de la Eurozona para los que se dispone de datos, tanto si pertenecen a la Unión Europea como si no, con el objetivo de tener una muestra lo más representativa posible del mercado europeo en su conjunto.

16. Como alternativa, podrían formarse las carteras ponderadas por valor de activo total, donde la cartera resultante recogería el riesgo de crédito medio dando un mayor peso a los bancos de mayor tamaño.

17. La alternativa es utilizar el procedimiento de Berndt y Obreja (2010), que consiste en valorar la estrategia que replica el contrato de CDS. De esta forma, se obtienen los rendimientos de los CDS spreads que capturan el riesgo de crédito debido a incrementos además de incorporar el nivel en la probabilidad de impago. Sin embargo, el cálculo resulta un tanto complejo. Además, Aretz y Pope (2013) muestran que al menos para sus datos, los resultados son similares de ambas formas. Una posible extensión sería comprobar si efectivamente el análisis de causalidad llevado a cabo en este trabajo conduce a los mismos resultados utilizando los rendimientos calculados siguiendo esta metodología.

18. La idea del procedimiento de causalidad de Granger viene explicado en Hamilton (1994) y Greene (2003). El análisis VAR y causalidad de Granger para investigar las relaciones de causalidad en el sector financiero han sido utilizadas por Galesi y Sgherri (2009) y Norden y Weber (2009), entre otros.

19. Hay que tener en cuenta que las funciones impulso-respuesta calculadas son simétricas y, por tanto, no distinguen entre shocks positivos y negativos. Una posible extensión del presente trabajo podría ser estudiar únicamente el impacto de los shocks positivos, ya que son los que implican un aumento en el nivel de CDS y por consiguiente del riesgo de crédito.

20. En este punto cabe preguntarse respecto a las relaciones de causalidad existentes entre los países pertenecientes a la zona Euro. Como posible extensión sería interesante analizar si existe una relación directa entre Grecia y el resto de países de la Eurozona o si por el contrario Grecia es un caso aislado.

\section{References}

Acharya, V. V., Drechsler, I., \& Schnabl, P. (2011). A Pyrrhic victory? Bank bailouts and sovereign credit risk (Working Paper, National Bureau of Economic Research). Disponible en http://www. nber.org/papers/w17136.pdf [consultado 10 de septiembre de 2014]

Alter, A., \& Schüler, Y. S. (2012). Credit spread interdependencies of European states and banks during the financial crisis. Journal of Banking and Finance, 36(12), 3444-3468. doi10.1016/j. jbankfin.2012.08.002

Aretz, K., \& Pope, P. F. (2013). Common factors in default risk across countries and industries. European Financial Management, 19(1), 108-152. doi:10.1111/j.1468-036X.2012.571.x 
Bernanke, B. (1986). Alternative explanations of the money-income correlation. Carnegie-Rochester Conference Series on Public Policy, 25, 49-100. doi:10.1016/0167-2231(86)90037-0

Berndt, A., \& Obreja, I. (2010). Decomposing European CDS returns. Review of Finance, 14, 189-233. doi:10.1093/rof/rfq004

Blanco, R., Brennan, S., \& Marsh, I. W. (2005). An empirical analysis of the dynamic relation between investment-grade bonds and credit default swaps. The Journal of Finance, 60(5), 2255-2281. doi10.1111/j.1540-6261.2005.00798.x

Byström, H. (2008). Credit default swaps and equity prices: The iTraxx CDS index market. In N. Wagner (Ed.), Credit risk - Models, derivatives, and management, financial mathematics series (Vol. 6, pp. 69-83). London: Chapman \& Hall.

Coudert, V., \& Gex, M. (2013). The interactions between the credit default swap and the bond markets in financial turmoil. Review of International Economics, 21(3), 492-505. doi10.1111/roie.12050

Dickey, D. A., \& Fuller, W. A. (1981). Likelihood ratio statistics for autoregressive time series with a unit root. Econometrica, 49, 1057-1072. doi:10.2307/1912517

Drudi, F., Durré, A., \& Mongelli, F. P. (2012). The interplay of economic reforms and monetary policy: The case of the eurozone. Journal of Common Market Studies, 50, 881-898. doi:10.1111/j.1468-5965.2012.02290.x

Ehlers, S., Gürtler, M., \& Olboeter, S. (2010). Financial crisis and information transfer - An empirical analysis of the lead-lag relationship between equity and CDS iTraxx indices (Working Paper). Disponible en http://papers.ssrn.com/sol3/papers.cfm?abstract_id=1585132 [consultado 10 de septiembre de 2014]

Ejsing, J. W., \& Lemke, W. (2011). The Janus-headed salvation: Sovereign and bank credit risk premia during 2008-2009. Economics Letters, 110(1), 28-31. doi10.1016/j.econlet.2010.10.001

Forte, S., \& Peña, J. I. (2009). Credit spreads: An empirical analysis on the informational content of stocks, bonds and CDS. Journal of Banking and Finance, 33(11), 2013-2025. doi10.1016/j. jbankfin.2009.04.015

Fung, H. G., Sierra, G. E., Yau, J., \& Zhang, G. (2008). Are the U.S. stock market and credit default swap market related? Evidence from the CDX indices. Journal of Alternative Investments, 11, 43-61. doi:10.3905/jai.2008.708849

Galesi, A., \& Sgherri, S. (2009). Regional financial spillovers across Europe: A global VAR analysis (International Monetary Fund Working Paper, WP/09/23). Washington, DC: International Monetary Fund.

Gentile, M., \& Giordano, L. (2012). Financial contagion during Lehman default and sovereign debt crisis: An empirical analysis on Euro area bond and equity markets. Journal of Financial Management, Markets and Institutions, 1(2), 197-224.

Gómez-Puig, M., \& Sosvilla-Rivero, S. (2013). Granger-causality in peripheral EMU public debt markets: A dynamic approach. Journal of Banking and Finance, 37(11), 4627-4649. doi10.1016/j.jbankfin.2013.05.002

González, M., \& Nave, J. M. (2010). Eficiencia de las técnicas de medición del riesgo de mercado ante situaciones de crisis. Revista Española de Financiación y Contabilidad, XXXIX(145), 41-64.

Granger, C. W. J. (1969). Investigating causal relations by econometric models and cross-spectral methods. Econometrica, 37(3), 424-438. doi:10.2307/1912791

Greene, W. H. (2003). Econometrics analysis. Upper Saddle River, NJ: Prentice Hall.

Hamilton, J. D. (1994). Time series analysis. Princeton, NJ: Princeton University Press.

Kalbaska, A., \& Gatkowski, M. (2012). Eurozone sovereign contagion: Evidence from the CDS market (2005-2010). Journal of Economic Behavior and Organization, 83, 657-673. doi:10.1016/j.jebo.2012.05.010

Mayordomo, S., Peña, J. I., \& Schwartz, E. S. (2014). Are all credit default swap databases equal? European Financial Management, 20, 677-713.

Norden, L., \& Weber, M. (2009). The co-movement of credit default swap, bond and stock markets: An empirical analysis. European Financial Management, 15, 529-562. doi:10.1111/j.1468036X.2007.00427.x

Pesaran, M. H., \& Shin, Y. (1998). Generalized impulse response analysis in linear multivariate models. Economics Letters, 58, 17-29. doi:10.1016/S0165-1765(97)00214-0

Phillips, P. C. B., \& Perron, P. (1988). Testing for a unit root in time series regression. Biometrica, 75, 335-346. doi:10.1093/biomet/75.2.335

Sims, C. A. (1986). Are forecasting models usable for policy analysis? Federal Reserve Bank of Minneapolis Quarterly Review, 10(1), 2-16. 
Apéndice 1.

Tabla A.1. Listado de bancos.

\begin{tabular}{|c|c|c|c|}
\hline País & Banco & Obs. & Activo total (miles euros) \\
\hline \multicolumn{4}{|l|}{ Zona Euro } \\
\hline \multirow[t]{3}{*}{ Alemania (3) } & Deutsche Bank & 1.626 & 2.155 .366 \\
\hline & Commerzbank & 1.626 & 657.609 \\
\hline & Deutsche Postbank & 1.626 & 191.578 \\
\hline \multirow[t]{2}{*}{ Austria (2) } & Erste Group Bank & 1.626 & 209.340 \\
\hline & Raiffeisen Zentralbank & 1.626 & 146.627 \\
\hline \multirow{2}{*}{ Bélgica (2) } & KBC Bank & 1.626 & 282.937 \\
\hline & Dexia & 1.626 & 412.051 \\
\hline \multirow[t]{6}{*}{ España (6) } & Banco Santander & 1.626 & 1.233 .765 \\
\hline & Banco Bilbao Vizcaya Argentaria & 1.626 & 591.356 \\
\hline & Banco Popular Español & 1.626 & 129.884 \\
\hline & Banco de Sabadell & 1.237 & 99.440 \\
\hline & Bankinter & 1.626 & 59.388 \\
\hline & Banco Pastor & 1.626 & 31.135 \\
\hline \multirow[t]{4}{*}{ Francia (4) } & BNP Paribas & 1.626 & 1.955 .940 \\
\hline & Société Générale & 1.626 & 1.176 .790 \\
\hline & Crédit Agricole & 1.626 & 1.718 .513 \\
\hline & Natixis & 1.626 & 504.495 \\
\hline \multirow[t]{4}{*}{ Grecia (4) } & National Bank of Greece & 656 & 105.560 \\
\hline & Alpha Bank & 1.626 & 57.681 \\
\hline & EFG Eurobank Ergasias & 1.626 & 75.096 \\
\hline & Piraeus Bank & 668 & 48.174 \\
\hline Holanda (1) & Rabobank & 1.626 & 652.536 \\
\hline \multirow[t]{7}{*}{ Italia (7) } & Unicredito Italiano & 1.626 & 914.108 \\
\hline & Intesa San Paolo & 1.626 & 626.898 \\
\hline & Banca Monte Paschi Siena & 1.626 & 234.029 \\
\hline & Unione di Banche Italiane & 1.626 & 127.445 \\
\hline & Banco Popolare & 1.626 & 130.861 \\
\hline & Banco Popolare Milano & 1.626 & 51.222 \\
\hline & Banca Italease & 1.257 & 12.482 \\
\hline \multirow[t]{3}{*}{ Portugal (3) } & Banco Espirito Santo & 1.626 & 79.525 \\
\hline & Banco Comercial Português & 1.626 & 91.918 \\
\hline & Banco Português de Investimento & 1.626 & 42.061 \\
\hline \multicolumn{4}{|l|}{ Zona No Euro } \\
\hline Dinamarca (1) & Danske Bank & 1.626 & 460.396 \\
\hline Noruega (1) & DNB NOR ASA & 1.015 & 274.365 \\
\hline \multirow[t]{4}{*}{ Suecia (4) } & Nordea Bank & 1.626 & 709.625 \\
\hline & Svenska Handelsbanken & 1.626 & 272.183 \\
\hline & Skandinaviska Enskilda Banken & 1.626 & 261.907 \\
\hline & Swedbank & 1.626 & 205.879 \\
\hline Suiza (1) & Credit Suisse Group & 1.626 & 847.570 \\
\hline \multirow[t]{6}{*}{ Reino Unido (6) } & HSBC Holdings PLC & 1.626 & 1.945 .118 \\
\hline & Lloyds Banking Group & 1.626 & 1.145 .210 \\
\hline & Standard Chartered & 1.626 & 456.713 \\
\hline & Barclays & 1.626 & 1.849 .925 \\
\hline & Royal Bank of Scotland Group & 1.626 & 1.781 .728 \\
\hline & HBOS & 1.626 & 541.354 \\
\hline Total (45) & & 69.873 & \\
\hline
\end{tabular}

Las entidades financieras están asignadas a países según clasificación de Datastream. Obs. hace referencia al número de observaciones disponibles (CDS spread) para cada banco de la muestra. El volumen de activo (Diciembre de 2011) está expresado en miles de euros. Para los países No Euro se ha utilizado el tipo de cambio medio proporcionado por Datastream a Diciembre de 2011. 
Reproduced with permission of the copyright owner. Further reproduction prohibited without permission. 